\title{
Antifungal Activities of Essential Oils from Six Conifers against Aspergillus fumigatus* ${ }^{* 1}$
}

\author{
Soo-Kyeong Jang ${ }^{* 2}$, Su-Yeon Lee*2, Seon-Hong Kim², Chang-Young Hong*2, \\ Mi-Jin Park ${ }^{* 3}$, and In-Gyu Choi ${ }^{* 2,4}$
}

\begin{abstract}
The antifungal activities of the essential oils from Pinus densiflora, Pinus koraiensis, Abies holophylla, Larix kaempferi, Cryptomeria japonica and Chamaecyparis obtusa against Aspergillus fumigatus were evaluated. Essential oils were extracted from each conifer leaves for $8 \mathrm{~h}$ using water distillation method. The essential oil from A. holophylla appeared the strongest antifungal activity among the six oils with MIC value $0.125 \mathrm{mg} / \mathrm{m} \ell$. The composition of the $A$. holophylla oil was analysed by GC/MS and then MIC was determined for main constituents of the oil. As the results, borneol and $\alpha$-bisabolol, which have a hydroxyl group, showed effective antifungal activities against $A$. fumigatus $(0.25 \mathrm{mg} / \mathrm{m} \ell)$. In addition, the synergistic antifungal effects were observed in the combination of borneol and $\alpha$-bisabolol.
\end{abstract}

Keywords : Essential oil, conifer, antifungal activity, Aspergillus fumigatus, synergistic effects

\section{INTRODUCTION}

Essential oils are natural complex compounds characterized by a strong odour with volatility, formed by aromatic plants as secondary metabolites (Bakkali et al., 2008). They are obtained from flowers, buds, seeds, leaves, bark, fruits and roots as aromatic oils (Burt, 2003). They are highly volatile in the air and their fragrances differ from every species or plant materials. In nature, essential oils play an important role in the protection of the plants as antibacterials, antivirals, antifungals, insecticides and herbivores by reducing their appetite for such plants (Han, 2007; Bakkali et al., 2008).

Accoriding to previous researches, some essential oils showed important antifungal activity against yeasts and dermatophytes fungi which

*1 Received on March 9, 2012; accepted on March 23, 2012

*2 Department of Forest Sciences, College of Agriculture \& Life Sciences, Seoul National University, Seoul 151-921, Korea

*3 Division of Wood Chemistry \& Microbiology, Department of Forest Resources Utilization, Korea Forest Research Institute, Seoul 130-712, Korea

*4 Research Institute for Agriculture and Life Sciences, College of Agriculture and Life Sciences, Seoul National University, 599 Gwanak-ro, Gwanak-gu, Seoul 151-921, Korea

† Corresponding author : In Gyu Choi (e-mail: cingyu@snu.ac.kr) 
could predict therapeutic benefits. The properties are magnified to treat the chronic diseases such as atopic dermatitis, asthma and an allergy. Many researches are being carried out to inhibit the food and plant pathogens (Salmonella enteritidis, Escherichia coli and Botrytis cinerea etc.) by using antimicrobial activities of essential oils (Farag et al., 1989; Hammer et al., 1999; MullerRiebau, et al., 1995; Pintore et al., 2002; SmithPalmer et al., 1998; Wilson et al., 1997).

The essential oils from conifers are also applied to the cosmetics and medicines and especially good antimicrobial properties of essential oils from Cryptomeria japonica and Chamaecyparis obtusa have been reported (Cheng et al., 2005). In addition, Pinus densiflora, Pinus koraiensis, Abies holophylla and Larix kaempferi which are widespread in East Asia were also used along with C. japonica and C. obtusa in this experiment.

Aspergillus fumigatus plays an essential role in recycling environmental carbon and nitrogen (Latge, 1999). Its natural ecological niche is the soil, wherein it survives and grows on organic debris (Latge, 1999: Mullins et al., 1976). But A. fumigatus is opportunistic pathogen that is responsible for infections in immunocompromised patients (Hope et al., 2007), and A. fumigatus infection was reported that it commonly manifests as invasive pulmonary aspergillosis (Ben-Ami et al., 2010). Furthermore invasive aspergillosis causes approximately $30 \%$ of fungal infections in patients dying with cancer (Bodey et al., 1992).

Previous results have shown that essential oils from some plants exhibit antifungal activity against Aspergillus strains (Han, 2007). However activity of conifer essential oils against $A$. fumigatus have not been reviewed so much. Therefore the purpose of our research was to evaluate the antifungal activities of conifer essential oils against $A$. fumigatus and inves- tigate action of their main compounds for the availability of conifers essential oils as forest resource in South Korea.

\section{MATERIALS and METHODS}

\subsection{Materials}

Leaves of six conifers, $P$. densiflora, $P$. koraiensis, A. holophylla, L. kaempferi, C. japonica and $C$. obtusa were collected in the Korea National Arboretum (KNA) in August 2011. Samples were extracted with $4 \ell$ distilled water by steam distillation method at $100^{\circ} \mathrm{C}$, for $8 \mathrm{~h}$.

\subsection{Test Organism}

In this test, A. fumigatus (KCCM 60331) was used, and maintained on malt extract agar medium (MEA, Bacto, USA) at $26^{\circ} \mathrm{C}$ then kept at $4^{\circ} \mathrm{C}$. Cultivated $A$. fumigatus was mixed with sterilized water to make fungal suspension. After homogenization, turbidity of the suspension was adjusted in according to McFarland standard No. 0.5.

\subsection{Essential Oils Analysis}

Essential oil of A. holophylla was analyzed by GC/MS on a Agilent $6890 \mathrm{GC}$ and DB-5 column (dimension $30 \mathrm{~m} \times 0.25 \mathrm{~mm}$, coating thickness of $0.25 \mu \mathrm{m}$ ) and carrier gas was He. The injector and detector were adjusted to 250 and $280^{\circ} \mathrm{C}$, respectively. The oven tem- perature was initiated at $50^{\circ} \mathrm{C}$ for $10 \mathrm{~min}$, in- creased by $5^{\circ} \mathrm{C} / \mathrm{min}$ to $280^{\circ} \mathrm{C}$ with final holding time of 10 min. Compounds were identified by comparison of each peak's mass spectra with those of authentic compounds in a mass spectra library by NIST (National Institute of Standards and Technology). 
Table 1. Addition of oils to the test plates.

\begin{tabular}{|c|c|c|c|c|c|c|c|c|c|c|}
\hline & 1 & 2 & 3 & 4 & 5 & 6 & 7 & 8 & 9 & 10 \\
\hline $\mathrm{mg} / \mathrm{ml}$ & 2 & 1 & 0.5 & 0.25 & 0.125 & 0.062 & 0.031 & 0.015 & 0.007 & 0.003 \\
\hline
\end{tabular}

Table 2. MIC of essential oils of six conifers against $A$. fumigatus

\begin{tabular}{cccccc}
\hline \multicolumn{7}{c}{ MIC $(\mathrm{mg} / \mathrm{m} \ell)$} \\
\hline \hline A. holophylla & P. densiflora & L. kaempferi & P. koraiensis & C. japonica & C. obtusa \\
0.125 & 0.25 & 0.5 & 0.5 & 0.5 & 0.5 \\
\hline
\end{tabular}

\subsection{Antifungal Activity by MIC (Minimum Inhibitory Concentra- tion)}

The effects of the essential oil from conifers and their constituents were evaluated using checkerboard titer tests (96 well). This plates were set up in accordance with the NCCLS (National Committee for Clinical Laboratory Standards) reference method. Essential oils of six conifers and constituents were prepared by two-fold serial dilution with dimethyl sulfoxide (DMSO) to final concentration from 2 to 0.003 $\mathrm{mg} / \mathrm{ml}$. Each well containing $100 \mu l$ of the oil of two fold concentration (Table 1) with $10 \mu l$ of A. fumigatus suspension. Two columns of growth controls (chemical blank) were included, with one row of the fungi blank. The plates were incubated at $26^{\circ} \mathrm{C}$ and were visually read after 4 days.

\section{RESULTS and DISCUSSIONS}

\subsection{Antifungal Activities of Essential Oils from Six Conifers}

The antifungal activities of essential oils from six conifers against $A$. fumigatus were shown in Table 2. MIC values were determined for $A$. holophylla $(0.125 \mathrm{mg} / \mathrm{ml}), P$. densiflora $(0.25$ $\mathrm{mg} / \mathrm{ml}$ ), and L. kaempferi, P. koraiensis, $C$. japonica and C. obtusa $(0.5 \mathrm{mg} / \mathrm{ml})$, respectively. The results of this study indicated that oils of $A$. holophylla had strong effective antifungal actions against $A$. fumigatus. Result of MIC was compared with the control group after 4 days. After one week later, growth of the fungi was not observed completely. Under the test conditions as described earlier, $A$. holophylla oil showed possession activity that was more fungicidal than fungi static by in vitro assay.

\subsection{Analysis of A. holophylla Essen- tial Oil}

The chemical constituents of essential oil from A. holophylla (AH) by $\mathrm{GC} / \mathrm{MS}$ analysis were shown in Table 3. Sixteen terpene compounds were detected and those amounts were reached to $99.34 \%$. The major constituents and their relative portions on essential oil were bornyl acetate $(19.42 \%)$, limonene $(16.78 \%)$, camphene $(10.65 \%), \alpha$-pinene $(10.44 \%), \alpha-$ bisabolol (5.80\%), borneol (5.37\%), $\beta$-pinene (5.21\%), caryophyllene $(1.77 \%)$ and humulene $(1.03 \%)$. And those chemical structures were shown in Fig. 1.

\subsection{Antifungal Activity of the Major Constituents of $\mathrm{AH}$ Essential Oil}

In this study, to screen for active constituent 
Soo-Kyeong Jang, Su-Yeon Lee, Seon-Hong Kim, Chang-Young Hong, Mi-Jin Park, and In-Gyu Choi

Table 3. Chemical composition of the essential oil from A. holophylla

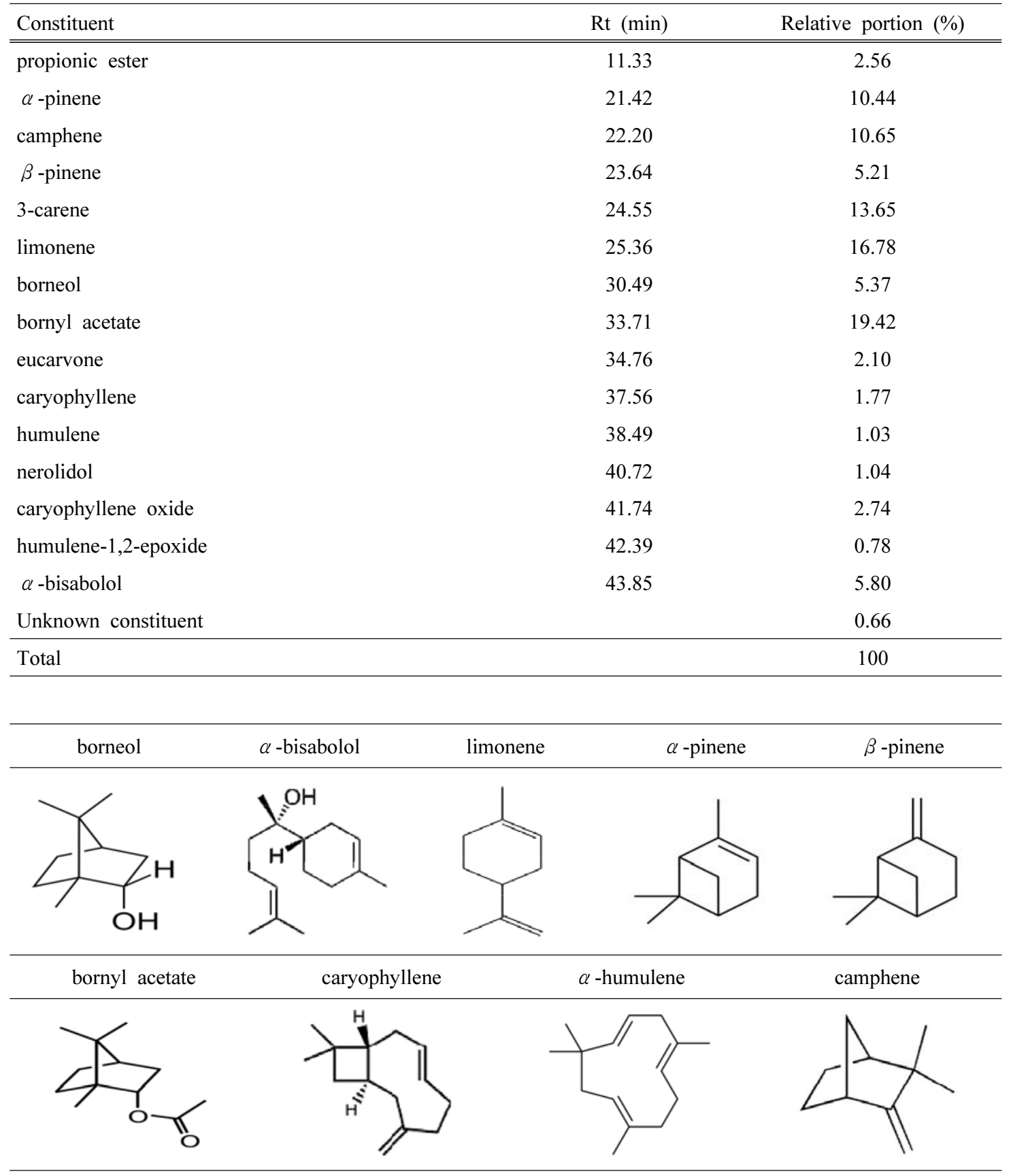

Fig. 1. Chemical structure of nine constituents from A. holophylla essential oil. 
Table 4. MIC values of $A$. holophylla essential oil constituents against $A$. fumigatus

\begin{tabular}{lc}
\hline Constituent & MIC $(\mathrm{mg} / \mathrm{m} \ell)$ \\
\hline \hline borneol & 0.25 \\
$\alpha$-bisabolol & 0.25 \\
limonene & 0.5 \\
$\alpha$-pinene & 0.5 \\
$\beta$-pinene & 0.5 \\
bornyl acetate & 0.5 \\
$\alpha$-humulene & 0.5 \\
camphene & 0.5 \\
caryophyllene & 0.5 \\
\hline
\end{tabular}

Table 5. MIC values of mixed constituents, ethanol and $A$. holophylla essential oil against $A$. fumigatus

\begin{tabular}{ccc}
\hline \multicolumn{3}{c}{ MIC $(\mathrm{mg} / \mathrm{m} \ell)$} \\
\hline \hline Mixed constituent & Ethanol & A. holophylla \\
0.125 & 0.5 & 0.125 \\
\hline
\end{tabular}

Mixed constituent : Mixing borneol with $\alpha$-bisabolol at $1: 1(\mathrm{v} / \mathrm{v})$ ratio.

that appeared antifungal activity, we used the main constituents as determined by GC/MS analysis of the oil. According to Table 4, MIC values ranged from 0.25 to $0.5 \mathrm{mg} / \mathrm{ml}$, and especially, borneol and $\alpha$-bisabolol showed strong antifungal activity $(0.25 \mathrm{mg} / \mathrm{m} \ell)$. However, the other single constituents did not show effective MIC value than crude AH oil.

The antifungal activities of each major constituent were weaker than that of the crude essential oil, because various groups of chemical compounds were contained within essential oils. It is probably that their antimicrobial activity is not attributable to one specific mechanism but there are several targets in the cell (Skandamis and Nychas, 2001; Carson et al.,
2002). The most representative roles of chemical compounds of essential oil were to damage to cytoplasmic membrane, membrane proteins so on (Knobloch et al., 1989; Sikkema et al., 1994; Oosterhaven et al., 1995; Ultee et al., 2000; 2002; Juven et al., 1994). Furthermore, not all of these mechanisms are separate targets; some are affected as a consequence of another mechanism being targeted (Burt, 2003). Another research reported that the crude essential oils appeared more positive effect than separating their compounds, because combination of various chemicals in essential oils lead to synergistic or antagonistic effects (Delaquis et al., 2002).

Borneol and $\alpha$-bisabolol were known as the terpene that containg a hydroxyl group. This fact led that the presence of the hydroxyl group in the constituents of essential oil affected the antifungal activity. The importance of the phenolic hydroxyl groups for the antimicrobial activity of the monoterpenes has previously been reported (Dorman et al., 2000; Ultee et al., 2002).

\subsection{Antifungal Activity of Combined Constituents}

To identify synergism of two alcohol group containing compounds to enhance the efficacy, checkerboard assays of mixed constituent, ethanol and $\mathrm{AH}$ oil were carried out. As shown in Table 5, the MIC of borneol combined with $\alpha$ bisabolol against $A$. fumigatus was decreased to $0.125 \mathrm{mg} / \mathrm{ml}$. The MIC value of combined constituent was lower than each single constituents of $\mathrm{AH}$ oil.

To enhance the efficacy of essential oils, the combined use of different oils has been evaluated recently for potential synergistic effects. In this study, we observe a similar effect from crude $\mathrm{AH}$ essential oil of antifungal activity by 
mixing borneol and $\alpha$-bisabolol with the ratio of $1: 1$. According to the results, we assumed that the combination of phenolic alcohol group containing constituents will probably results in a more strong antifungal activity.

According to previous researches, it is difficult to know what constituents of essential oils affecting the antifungal activities accurately. In other words, the mechanism of action by the antimicrobial properties of essential oils and their components have not been studied in great detail (Lambert et al., 2001). In this study, it is supposed that the antifungal activity of $\mathrm{AH}$ oil against $A$. fumigatus can be related to the presence of borneol and $\alpha$-bisabolol which is contained phenolic hydroxyl group.

MIC was evaluated using ethanol against $A$. fumigatus to figure out how the presence of hydroxyl group influenced the antifungal activity. But the activity of ethanol with MIC value $0.5 \mathrm{mg} / \mathrm{ml}$ was much inferior to the mixture of borneol and $\alpha$-bisabolol or crude essential oil from AH. This results showed that the hydroxyl group in constituents of essential oil was not mandatory for antifungal activity. Based on these data, the phenolic ring structures in monoterpene compounds affected the antifungal activity instead of hydroxyl group. However it is not reasonable assumption, because of considering a study on the antimicrobial activity using a linalool (Alviano et al., 2005). Thus, it is assumed that both hydroxyl group in constituent of essential oil and a unique chemical structures of each constituent contributed to good antifungal activity of borneol, $\alpha$-bisabolol and their mixture.

\section{CONCLUSION}

In this study, the antifungal activities of essential oils from A. holophylla, $P$. densiflora, $L$. kaempferi, P. koraiensis, C. japonica and $C$. obtusa were examined. Among the oils, A. holophylla showed the strongest antifungal action against $A$. fumigatus.

According to the analysis of chemical compounds in essential oil from $A$. holophylla by GC/MS, major constituents were selected to examine MIC values. As a result, borneol and $\alpha$-bisabolol showed the lowest MIC value. Therefore the strong effect of $\mathrm{AH}$ essential oil was appeared due to the content of borneol and a-bisabolol defined as strong antifungal agent. Although a positive effect against A. fumigatus was appeared from two constituents, it was not indispensable factor to antifungal activity. However the positive effect of borneol and $\alpha$ bisabolol was may explained by their chemotype with hydroxyl group in structure. Interestingly, the antifungal activity of the combination of borneol and $\alpha$-bisabolol was similar to crude essential oil from A. holophylla. This meant that the mixture of some constituents also could obtain a strong activity against fungi, although antifungal activities of essential oils were dependent on a synergistic effect of their a number of constituents.

In conclusion, this study suggested that the possibility on utilization of essential oils from conifers as antifungal agent. Further studies about a side effect or stability in the body of essential oils are necessary for pharmaceutical purpose.

\section{ACKNOWLEDGEMENT}

This study was carried out with a grant from the Forest Science and Technology Projects (S1 11011L040120) funded by the Korean Forest Service.

\section{REFERENCE}

1. Bakkali, F., S. Averbeck, D. Averbeck, and M. 
Idaomar. 2008. Biological effects of essential oils - A review. Food and Chemical Toxicology 46 (2): $446 \sim 475$.

2. Burt, S. 2003. Essential oils: their antibac- terial properties and potential applications in foods-a review. International Journal of Food Microbiology 94(1): $223 \sim 253$

3. Han, K. H. 2007. Antifungal Activity of Essential Oil from Asarum sieboldii against Epidermal and Opportunistic Pathogenic Fungi. The Korean Journal of Mycology 35(1): $58 \sim 60$.

4. Farag, R. S., Z. Y. Daw, F. M. Hewedi, and G. S. A. El-Baroty. 1989. Antimicrobial activity of some Egyptian spice essential oils. Journal of Food Protection 52(9): 665 667.

5. Hammer, K. A., C. F. Carson, and T. V. Riley. 1999. Antimicrobial activity of essential oils and other plant extracts. Journal of Applied Microbiology 86(6): 985 990.

6. Muller-Riebau, F., B. Berger, and O. Yegen, 1995. Chemical composition and fungitoxic properties to phytopathogenic fungi of essential oils of selected aromatic plants growing wild in Turkey. J. Agric. Food Chem. 43(8): 2262 2266.

7. Pintore, G., M. Usai, P. Bradesi, C. Juliano, G. Boatto, F. Tomi, M. Chessa, R. Cerri, and J. Casanova. 2002. Chemical composition and antimicrobial activity of Rosmarinus officinalis L. oils from Sardinia and Corsica. Flavour and Fragrance Journal 17(1): $15 \sim 19$.

8. Smith-Palmer, A., J. Stewart, and L. Fyfe. 1998. Antimicrobial properties of plant essential oils and essences against five important food-borne pathogens. Letters in Food Microbiology 26(2): $118 \sim 122$.

9. Wilson, C. L., J. M. Solar, A. El Ghaouth, and M. E. Wisniewski, 1997. Rapid evaluation of plant extracts and essential oils for antifungal activity against Botrytis cinerea. Plant Dis. 81(2): $204 \sim 210$.

10. Cheng, S. S., H. Y. Lin, and S. T. Chang. 2005. Chemical Composition and Antifungal Activity of Essential Oils from Different Tissues of Japanese Cedar (Cryptomeria japonica). J. Agric. Food Chem. 53(3): 614 619.

11. Latge, J. P. 1999. Aspergillus fumigatus and aspergillosis. Clin. Microbiol. Rev. 12(2): 310 350 .

12. Mullins, J., R. Harvey, and A. Seaton. 1976. Sources and incidence of airborne Aspergillus fumigatus (Fres). Clin. Allergy 6(3): 209 217.

13. Hope, W. W., M. J. Kruhlak, C. A. Lyman, R. Petraitiene, V. Petraitis, A. Francesconi, M. Kasai, D. Mickiene, T. Sein, and J. Peter. 2007. Pathogenesis of Aspergillus fumigatus and the kinetics of galactomannan in an in vitro model of early invasive pulmonary aspergillosis: implications for antifungal therapy. Journal of Infectious Diseases 195(3): 455.

14. Ben-Ami, R., R. E. Lewis, and D. P. Kontoyiannis. 2010. Enemy of the (immunosuppressed) state: an update on the pathogenesis of Aspergillus fumigatus infection. Br. J. Haematol 150 (4): $406 \sim 417$.

15. Bodey, G., B. Bueltmann, W. Duguid, D. Gibbs, H. Hanak, M. Hotchi, G. Mall, P. Martino, F. Meunier, S. Milliken, S. Naoe, M. Okudaira, D. Scevola, and J. van't Wout. 1992. Fungal infections in cancer patients: an international autopsy survey. Eur. J. Clin. Microbiol. Infect. Dis. 11 (2): $99 \sim 109$.

16. Skandamis, P. N. and G. J. E. Nychas. 2001. Effect of oregano essential oil on microbiological and physico-chemical attributes of minced meat stored in air and modified atmospheres. Journal of Applied Microbiology 91(6): 1011 1022.

17. Carson, C. F., B. J. Mee, and T. V. Riley. 2002. Mechanism of action of Melaleuca alternifolia (tea tree) oil on Staphylococcus aureus determined by time-kill, lysis, leakage and salt tolerance assays and electron microscopy. Antimicrobial Agents and Chemotherapy 46(6): 1914 1920.

18. Knobloch, K., A. Pauli, B. Iberl, H. Weigand, and N. Weis. 1989. Antibacterial and antifungal properties of essential oil components. Journal of Essential Oil Research 1: 119 128.

19. Sikkema, J., J. A. M. De Bont, and B. Poolman. 1994. Interactions of cyclic hydrocarbons with biological membranes. Journal of Biological Chemistry 269(11): $8022 \sim 8028$.

20. Oosterhaven, K., B. Poolman, and E. J. Smid. 1995. S-carvone as a natural potato sprout inhi- 
Soo-Kyeong Jang, Su-Yeon Lee, Seon-Hong Kim, Chang-Young Hong, Mi-Jin Park, and In-Gyu Choi

biting, fungistatic and bacteristatic compound. Industrial Crops and Products 4(1): $23 \sim 31$.

21. Ultee, A., E. P. W. Kets, M. Alberda, F. A. Hoekstra, and E. J. Smid. 2000. Adaptation of the food-borne pathogen Bacillus cereus to carvacrol. Archives of Microbiology 174(4): 233 238.

22. Ultee, A., M .H. J. Bennink, and R. Moezelaar. 2002. The phenolic hydroxyl group of carvacrol is essential for action against the food-borne pathogen Bacillus cereus. Applied and Environmental Microbiology 68(4): $1561 \sim 1568$.

23. Juven, B. J., J. Kanner, F. Schved, and H. Weisslowicz. 1994. Factors that interact with the antibacterial action of thyme essential oil and its active constituents. Journal of Applied Bacteriology 76(6): 626 631.

24. Delaquis, P. J., K. Stanich, B. Girard, and G. Mazza. 2002. Antimicrobial activity of individual and mixed fractions of dill, cilantro, coriander and eucalyptus essential oils. International Journal of Food Microbiology 74(1-2): 101 109.

25. Dorman, H. J. D. and S. G. Deans. 2000 Antimicrobial agents from plants: antibacterial activity of plant volatile oils. Journal of Applied Microbiology 88(2): 308 316.

26. Lambert, R. J. W., P. N. Skandamis, P. Coote, and G. J. E. Nychas. 2001. A study of the minimum inhibitory concentration and mode of action of oregano essential oil, thymol and carvacrol. Journal of Applied Microbiology 91 (3): $453 \sim 462$.

27. Alviano, W. S., R. R. Mendonça-Filho, D. S. Alviano, H. R. Bizzo, T. Souto-Padrón, M. L. Rodrigues, A. M. Bolognese, C. S. Alviano, and M. M. G. Souza. 2005. Antimicrobial activity of Croton cajucara Benth linalool-rich essential oil on artificial biofilms and planktonic microorganisms. Oral Microbiol Immunol. 20(2): 101 105 . 